\title{
Dynamic Stabilization of the Lumbar Spine using the Dynesys ${ }^{\circledR}$ System
}

\author{
Goktug AKYOLDAS ${ }^{1}$, Orhun Mete CEVIK², Tuncer SUZER ${ }^{1}$, Mehdi SASANI ${ }^{1}$, Tunc OKTENOGLU1', Ali Fahir OZER ${ }^{1}$ \\ ${ }^{1}$ Koc University School of Medicine, Department of Neurosurgery, Istanbul, Turkey \\ ${ }^{2}$ Bakirkoy Training and Research Hospital, Department of Neurosurgery, Istanbul, Turkey
}

Corresponding author: Ali Fahir OZER alifahirozer@gmail.com

\section{ABSTRACT}

AIM: To present the clinical results in patients with minor instability with "Dynesys ${ }^{\circledR}$ " a soft spinal stabilization system.

MATERIAL and METHODS: A total of 83 patients were operated upon and the Dynesys ${ }^{\circledR}$ system was applied. Indications for surgery included painful degenerative disc disease, degenerative spondylolisthesis and lumbar canal stenosis.

RESULTS: The results for the Dynesys ${ }^{\circledR}$ system were satisfactory, and we have calculated the overall complication rate to be $20.4 \%$ $(n=17)$, which is in agreement with the literature.

CONCLUSION: The Dynesys ${ }^{\circledR}$ dynamic stabilization system effectively protects lumbar motion and achieves lumbar stability in patients with lumbar spinal problems. Our clinical result support literature that Dynesys ${ }^{\circledR}$ system is a strong alternative to fusion and instrumentation system in patient with chronic instabilities.

KEYWORDS: Dynamic stabilization, Degenerative disc disease, Lumbar stenosis, Degenerative spondylolisthesis

\section{INTRODUCTION}

$\mathrm{P}$ osterolateral fixation with pedicle screws and rods has become the prominent intervention for the surgical treatment of spinal disorders such as spinal instability, degenerative disorders, vertebral fractures, malignancy, deformities and infections $(2,3,6,27)$. One of the most important drawbacks of solid fixation and fusion is the decreased range of motion in the fused levels. In addition, adjacent segment degeneration (ASD) is another important postoperative complication $(16,20)$. The dynamic neutralization system (Dynesys ${ }^{\circledR}$, Zimmer $\mathrm{CH}$ ) was designed as an alternative to spinal solid fixation in an effort to reduce ASD and maintain physiologic motion and function in select cases $(15,16,22,26)$.

In this study, we present the clinical outcomes and complications of 83 patients who underwent surgery with the Dynesys ${ }^{\circledR}$ dynamic stabilization system (Zimmer Inc, Warsaw, IN, USA) and review the associated literature.

\section{MATERIAL and METHODS}

We retrospectively reviewed the cases of 83 patients with various spinal disorders who underwent surgery with the Dynesys $^{\circledR}$ dynamic stabilization system between 2011 and 2016. Painful degenerative disc disease, degenerative spondylolisthesis and lumbar canal stenosis were indications for surgery. Radiologic and clinical follow-ups were documented separately. Patient demographic data, radiologic examinations and patient case notes were reviewed. The visual analog scale for leg pain (VAS-LP) and back pain (VAS-BP) and ODI were used to assess the pain levels and disability of the patients.

All patients received general anesthesia and were in the prone position for operations. The Dynesys ${ }^{\circledR}$ system was implanted either through a Wiltse approach or a midline incision. Prophylactic Cefuroxime was administered to all patients upon initiation of anesthesia and was continued during the following 48 hours. Patients were mobilized on the first
Goktug AKYOLDAS (1D): 0000-0003-4234-6520

Orhun Mete CEVIK (1D : 0000-0001-9898-3807

Tuncer SUZER (1) : 0000-0001-7431-0579
Mehdi SASANI

Tunc OKTENOGLU

Ali Fahir OZER
(D) : 0000-0003-0962-3530

(1) : $0000-0002-7672-5994$

(Di) : 0000-0001-7285-381X 
postoperative day and discharged after 4 to 5 days. Clinical and radiological follow-ups were recorded at 6, 12 and 24 months after surgery. Imaging of an applied Dynesys ${ }^{\circledR}$ system is presented in Figure $1 \mathrm{~A}-\mathrm{C}$.

\section{RESULTS}

The Dynesys ${ }^{\circledR}$ dynamic system was implanted in 83 consecutive patients between 2011 and 2016. There were 52 female patients and 31 male patients. The mean age was 52.5

Table I: Demographic Data of Patients

\begin{tabular}{lc}
\hline Number of Patients & 83 \\
\hline Sex Ratio (women/men) & $50 / 33$ \\
\hline Age at Operation & $50.2(21-85)$ \\
\hline
\end{tabular}

Total Clinical Follow-up 46 months (32-90 months)

\begin{tabular}{|c|c|c|}
\hline & Discopathy & 45 \\
\hline \multirow[t]{4}{*}{ Indications } & Instability & 21 \\
\hline & Previous Surgery & 17 \\
\hline & 1 & 55 \\
\hline & 2 & 10 \\
\hline \multirow[t]{3}{*}{ Number of Segments } & 3 & 8 \\
\hline & 4 & 2 \\
\hline & $5+$ & 8 \\
\hline Total Screws & 484 & \\
\hline
\end{tabular}

(range between 21 and 85). Twenty-one patients underwent surgery due to instability and 45 patients were operated on due to discopathy. Seventeen patients had previous spine surgery. A total of 484 screws, $7 \mathrm{~mm}$ in diameter, were implanted. Mean clinical follow-up was 46 months (range between 32 and 90 months). Demographic data of patients are presented in Table I.

In our series, a significant clinical improvement was observed after surgery. Preoperative visual analog scales for back pain (VAS-BP) and leg pain (VAS-LP) were $7.6 \pm 0.84$ and $7.7 \pm 0.85$, respectively. VAS-BP was $2.5 \pm 0.44$ at the 6 -month follow-up, $1.5 \pm 0.32$ at the 1-year follow-up and $1.5 \pm 0.28$ at 2-year follow-up. VAS-LP was $2.3 \pm 0.42$ at the 6 -month follow-up, $1.5 \pm 0.34$ at the 1-year follow-up and $0.8 \pm 0.22$ at 2-year follow-up (Table II). Meanwhile, the ODI scores improved significantly after surgery at 24-month post-operation when compared to pre-operation. Preoperative ODI scores were $23.4 \pm 9.9$ before surgery. Six-month, 1-year and 2-year after surgery, ODI scores were $4.2 \pm 2.2,3.3 \pm 1.2$ and $2.9 \pm 0.9$, respectively (Table II).

No reoperations were required in the postoperative period due to screw malposition. Our screw-loosening rate was $6 \%$ $(n=5)$ and breakage rate was $3.6 \%(n=3)$. We also found ASD in $4.8 \%$ of patients $(n=4)$. No reoperations were required due to ASD. In this study, the infection rate was $5.9 \%(n=5)$. All the patients who had postoperative infections had instrumentation of five levels or more. The infection rate was $0 \%(n=75)$ in cases involving four or fewer segments. The reoperation rate was $8.4 \%(n=7)$. Three patients underwent reoperation due to screw breakage and four due to operation site infection. In our study, the overall complication rate was $20.4 \%(n=17)$.

Table II: VAS and ODI Scores of the Patients

\begin{tabular}{lcccc}
\hline & Preoperative & $\begin{array}{c}\text { Postoperative } \\
\text { 6 Months }\end{array}$ & $\begin{array}{c}\text { Postoperative } \\
\text { 12 Months }\end{array}$ & $\begin{array}{c}\text { Postoperative } \\
\text { 24 Months }\end{array}$ \\
\hline VAS-BP & $7.6 \pm 0.84$ & $2.5 \pm 0.44$ & $1.5 \pm 0.32$ & $1.5 \pm 0.28$ \\
\hline VAS-LP & $7.6 \pm 0.84$ & $2.3 \pm 0.42$ & $1.5 \pm 0.34$ & $0.8 \pm 0.22$ \\
\hline ODI & $23.4 \pm 9.9$ & $4.2 \pm 2.2$ & $3.3 \pm 1.2$ & $2.9 \pm 0.9$ \\
\hline
\end{tabular}

VAS: Visual analogue scale, ODI: Oswestry disability index, BP: Back pain, LP: Leg pain.
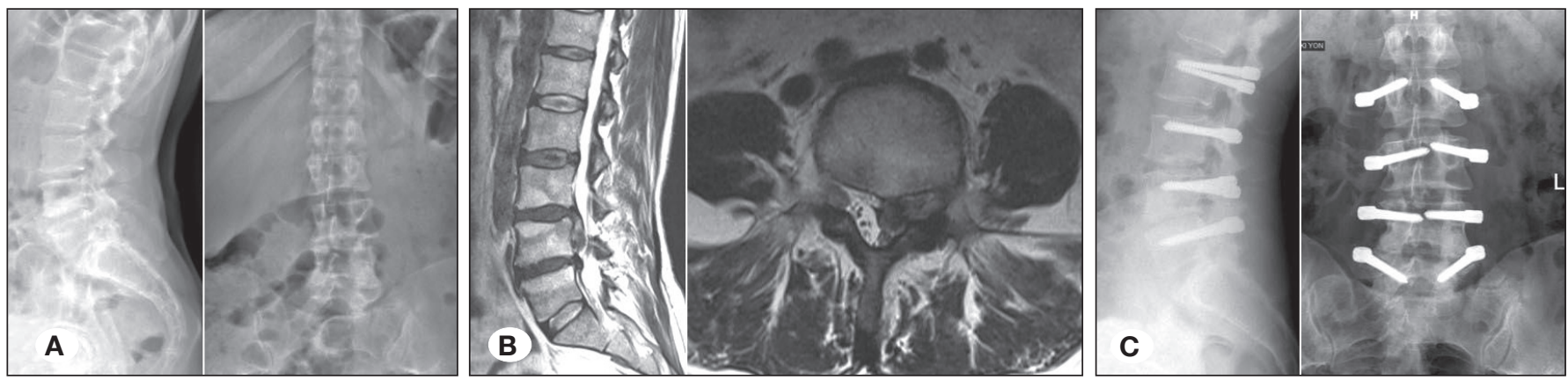

Figure 1: 46-year-old female was admitted to our clinic with complaints of back and left leg pain. X-rays reveal apparent calcification at the L3-4 and L4-5 levels (A). MR scans reveal a large L4-5 disc herniation with Modic degeneration on both levels (B). Dynamic stabilization was performed on these levels (C). 


\section{DISCUSSION}

Dynamic stabilization systems (DSS) have been developed to permit restricted motion across a functional spinal unit. Additionally, the theory behind DSS is to reduce loading of the facet joints and to preserve the operated segment kinematics. Dubois et al. were the first to present the Dynesys $^{\circledR}$ dynamic stabilization system $(8,11)$. The Dynesys ${ }^{\circledR}$ Spinal System (Zimmer Spine, Minneapolis, MN, USA) is a dynamic transpedicular screw-based fixation system with elastic interconnection parts; it involves restoration of the biomechanics of the posterior annulus and facet joints, thus allowing for the reconstitution of the natural balance between the posterior muscular structures and the intervertebral disc (24). It was shown that progression of minor deformities secondary to spinal stenosis with degenerative scoliosis, and early degenerative spondylolisthesis could be treated with the Dynesys $^{\circledR}$ system (28). Surgeons typically use the Dynesys ${ }^{\circledR}$ system as a single level implant; however, up to 4 segments can be treated $(23,29)$. In our study, 10 patients underwent stabilization of 4 or more segments with Dynesys ${ }^{\circledR}$.

The mobility of instrumented segments after DSS plays an important role in improving the quality of life $(12,14,22,25,28)$. In this study, the majority of patients were satisfied with the results of the surgery. The patients were mobilized on the first postoperative day and discharged within 4 to 5 days. Moreover, patients displayed significant improvement in VAS and ODI score at 6-month, 1- and 2-year follow-ups.

Despite the advantages of the Dynesys ${ }^{\circledR}$ system, reoperation may be necessary due to several complications. An overall complication rate of $0 \%$ to $24 \%$ with the Dynesys ${ }^{\circledR}$ system has been reported $(22,23,29)$. Our overall complication rate was comparable at $20.4 \%(n=17)$. The most common complications were screw breakage and loosening (21). Pham et al. recently presented a comprehensive review. They reported the overall screw loosening rate as $11.6 \%$ and breakage rate as $1.6 \%$ (21). In our study, loosening and screw breakage rates were as low as $6 \%$ and $3.6 \%$, respectively. These rates suggest that the Dynesys ${ }^{\circledR}$ system minimizes the incidence of screw breakage by offering more flexibility than solid fixation. Reported reoperation rates secondary to complications range from $4.8 \%$ to $19 \%(12,21,28,29)$. Our reoperation rate was comparable at $8.4 \%(n=7)$.

One of the major complications associated with implant systems is postoperative surgical site infection. Postoperative infection cause chronic back pain, increased deformity, prolonged hospital stays, and higher hospital costs $(4,7,13,18)$. Compared to the majority of posterior arthrodesis procedures, those involving Dynesys ${ }^{\circledR}$ frequently have a lower postoperative infection rate for the system is less invasive $(5,21,22,28)$. Pham et al. reported an overall infection rate of $4.6 \%$ (21). Our overall surgical site infection rate was slightly higher at $5.9 \%(n=5)$. All of the five patients who developed postoperative infections had undergone five or more levels instrumentation. Lutz et al. reported a high rate of infection $(22 \%)$ in patients with the Dynesys ${ }^{\circledR}$ system in the long-term follow-up period; however, they did not find any correlation between the operated level and infection rate in their Dynesys ${ }^{\circledR}$ series as we did in our study (17).

In our series, the infection rate was $0 \%$ (75 of 83 patients) in short levels (4 or less), whereas patients with long levels of instrumentation (5 or more) had a high infection rate of $62.5 \%$ (5 of 8 patients) (1).

It is assertive to suggest that dynamic systems, including Dynesys ${ }^{\circledR}$, preserve spinal motion and create a suitable environment for spine physiology. We have previously reported that motion similar to that of a normal spine can be achieved when dynamic rods are used together with dynamic screws $(9,19)$. In the literature, there are many clinical and experimental reports showing that the Dynesys ${ }^{\circledR}$ system is very effective for stabilizing the impaired motion segment in patients who have one or two affected lumbar segments. Complications typically occur when the system is used in three or more unstable segments. Preserving the motion and stabilizing the spine are the main objectives in dynamic systems; however, we cannot obtain these results in all patients. In patients with severely damaged stability, fusion risk after dynamic stabilization is higher than in patients with moderately damaged stability. In our own published experience, we found that if a dynamic system is used in cases of advanced degenerative disc disease, the degenerated disc proceeds to fusion under the control of the dynamic system, but rehydration has improved in patients with a less degenerate disc disease (30-32).

With a review of our previous clinical results along with the literature data, for select cases, the Dynesys ${ }^{\circledR}$ system can be claimed to be superior to fusion. First, it is a simple and easy system for surgeons to apply compared to fusion procedures. Second, in the cases of suboptimal results or complications with Dynesys ${ }^{\circledR}$, it is possible to change the system and perform a fusion. On the contrary, once a fusion operation is performed, the result is permanent, and cannot be converted to a dynamic system. This is one of the most important advantages of all dynamic stabilization systems.

It should be noted that our study had some limitations. First, our study is retrospective with inherent design limitations. Second, our study had no control group, such as patients who underwent surgery with a different rigid or dynamic instrumentation system. We are therefore planning additional studies that aim to include control groups and larger patient numbers.

\section{CONCLUSION}

The Dynesys ${ }^{\circledR}$ dynamic stabilization system is effective in preserving lumbar motion and achieving lumbar stability in patients who have lumbar spinal problems. Moreover, motion preservation also reduces the risks of pseudoarthrosis and adjacent segment disease, which are unfortunately not rare after fusion surgery. Lumbar stabilization without fusion is particularly effective in cases involving up to two unstable segments. 


\section{REFERENCES}

1. Akyoldas G, Yilmaz A, Aydin AL, Oktenoglu T, Sasani M, Suzer T, Akiz C, Ozer AF: High infection rates in patients with longsegment Dynesys ${ }^{\circledR}$ system. World Neurosurg 119:403-406, 2018

2. Ashman RB, Galpin RD, Corin JD, Johnston CE: Biomechanical analysis of pedicle screw instrumentation systems in a corpectomy model. Spine 14:1398-1405, 1989

3. Benzel EC, Baldwin NG: Crossed-screw fixation of the unstable thoracic and lumbar spine. J Neurosurg 82:11-16, 1995

4. Bible JE, Biswas D, Devin CJ: Postoperative infections of the spine. Am J Orthop 40:264-271, 2011

5. Bordes-Monmeneu M, Bordes-Garcia V, Rodrigo-Baeza F, Saez D: System of dynamic neutralization in the lumbar spine: Experience on 94 cases. Neurocirugia (Astur) 16(6):499-506, 2005

6. Brodke DS, Bachus KN, Mohr RA, Nguyen BK: Segmental pedicle screw fixation or cross-links in multilevel lumbar constructs. A biomechanical analysis. Spine J 1:373-379, 2001

7. Chaichana KL, Bydon M, Santiago-Dieppa DR, Hwang L, McLoughlin G, Sciubba DM, Wolinsky JP, Bydon A, Gokaslan ZL, Witham T: Risk of infection following posterior instrumented lumbar fusion for degenerative spine disease in 817 consecutive cases. J Neurosurg Spine 20:45-52, 2014

8. Dubois B, de Germay B, Schaerer N, Fennema P: Dynamic neutralization: A new concept for restabilization of the spine. In: Szpalski MGR, Pope MH (ed), Lumbar Segmental Instability. Philadelphia, PA: Lippincott Williams and Wilkins, 1999:233-240

9. Erbulut DU, Kiapour A, Oktenoglu T, Ozer AF, Goel VK: A computational biomechanical investigation of posterior dynamic instrumentation: Combination of dynamic rod and hinged (dynamic) screw. J Biomech Eng 136(5):051007, 2014

10. Fayyazi $\mathrm{AH}$, Ordway NR, Park SA, Fredrickson BE, Yonemura $\mathrm{K}$, Yuan HA: Radiostereometric analysis of postoperative motion after application of dynesys dynamic posterior stabilization system for treatment of degenerative spondylolisthesis. J Spinal Disord Tech 23:236-241, 2010

11. Freudiger S, Dubois G, Lorrain M: Dynamic neutralization of the lumbar spine confirmed on a new lumbar spine simulator in vitro. Arch Orthop Trauma Surg 119:127-132, 1999

12. Fritzell $P$, Hagg $O$, Wessberg $P$, Nordwall $A$ : Chronic low back pain and fusion: A comparison of three surgical techniques: A prospective multicenter randomized study from the Swedish lumbar spine study group. Spine (Phila Pa 1976) 27(11):11311141, 2002

13. Gerometta A, Rodriguez Olaverri JC, Bitan F: Infections in spinal instrumentation. Int Orthop 36:457-464, 2012

14. Grob D, Benini A, Junge A, Mannion AF: Clinical experience with the Dynesys semirigid fixation system for the lumbar spine: Surgical and patient-oriented outcome in 50 cases after an average of 2 years. Spine (Phila Pa 1976) 30(3):324331,2005

15. Lee SE, Jahng TA, Kim HJ: Decompression and nonfusion dynamic stabilization for spinal stenosis with degenerative lumbar scoliosis: Clinical article. J Neurosurg Spine 21:585594,2014
16. Lee SE, Park SB, Jahng TA, Chung CK, Kim HJ: Clinical experience of the dynamic stabilization system for the degenerative spine disease. J Korean Neurosurg Soc 43:221226, 2008

17. Lutz JA, Otten P, Maestretti G: Late infections after dynamic stabilization of the lumbar spine with Dynesys. Eur Spine J 21(12):2573-2579, 2012

18. Meredith DS, Kepler CK, Huang RC, Brause BD, BoachieAdjei O: Postoperative infections of the lumbar spine: Presentation and management. Int Orthop 36:439-444, 2012

19. Oktenoglu T, Erbulut DU, Kiapour A, Ozer AF, Lazoglu I, Kaner T, Sasani M, Goel VK: Pedicle screw-based posterior dynamic stabilisation of the lumbar spine: In vitro cadaver investigation and a finite element study. Comput Methods Biomech Biomed Engin 18(11):1252-1261, 2015

20. Park P, Garton HJ, Gala VC, Hoff JT, McGillicuddy JE: Adjacent segment disease after lumbar or lumbosacral fusion: Review of the literature. Spine 29:1938-1944, 2004

21. Pham MH, Mehta VA, Patel NN, Jakoi AM, Hsieh PC, Liu JC, Wang JC, Acosta FL: Complications associated with the Dynesys dynamic stabilization system: A comprehensive review of the literature. Neurosurg Focus 40(1):2, 2016

22. Putzier M, Schneider SV, Funk JF, Tohtz SW, Perka C: The surgical treatment of the lumbar disc prolapse: Nucleotomy with additional transpedicular dynamic stabilization versus nucleotomy alone. Spine (Phila Pa 1976) 30(5):109-114, 2005

23. Schwarzenbach O, Berlemann U: Dynamic posterior stabilization with the pedicle screw system DYNESYS. Oper Orthop Traumatol 22(5-6):545-557, 2010

24. Schwarzenbach O, Berlemann U, Stoll ThM, Dubois G: Posterior dynamic stabilization systems: Dynesys. Orthop Clin N Am 36:363-372, 2005

25. Schwarzenbach O, Launer R, Els M: Dynamic neutralization with DYNESYS for the treatment of degenerative spine disease. Eur Spine J (10):57, 2001

26. Sengupta DK: Point of view: Dynamic stabilization in addition to decompression for lumbar spinal stenosis with degenerative spondylolisthesis. Spine (Phila Pa 1976) 31:450, 2006

27. Shin TS, Kim HW, Park KS, Kim JM, Junk CK: Short-segment pedicle instrumentation of thoracolumbar burst-compression fractures; short term follow-up results. J Korean Neurosurg Soc 42(4):265-270, 2007

28. Stoll TM, Dubois G, Schwarzenbach O: The dynamic neutralization system for the spine: A multi-center study of a novel non-fusion system. Eur Spine J 11:170-178, 2002

29. Würgler-Hauri CC, Kalbarczyk A, Wiesli $M$, Landolt $H$, Fandino J: Dynamic neutralization of the lumbar spine after microsurgical decompression in acquired lumbar spinal stenosis and segmental instability. Spine (Phila Pa 1976) 33(3):66-72, 2008

30. Yilmaz A, Senturk S, Sasani M, Oktenoglu T, Yaman O, Yildirim H, Suzer T, Ozer AF: Disc rehydration after dynamic stabilization: A report of 59 cases. Asian Spine J 11(3):348355, 2017

31. Zhang Y, Shan JL, Liu XM, Li F, Guan K, Sun TS: Comparison of the dynesys dynamic stabilization system and posterior lumbar interbody fusion for lumbar degenerative disease. PLoS One 11(1):e0148071, 2016

32. Zhang Y, Zhang ZC, Li F, Sun TS, Shan JL, Guan K, Zhao GM, Zhang LZ: Long-term outcome of dynesys dynamic stabilization for lumbar spinal stenosis. Chin Med J (Engl) 131:2537-2543, 2018 